\title{
Study on Revision of Pedestrian Road Design Guideline in Korea
}

\author{
Woo Hoon Jeon and Inchul Yang
}

\begin{abstract}
Despite of many efforts, there is still insufficient infrastructure for pedestrians. Pedestrian traffic accidents are 4.1 per 100,000 population, which is three times higher than the OECD average of 1.4 in Korea. In particular, the entrance to a village on a national highway or the vicinity of a school is an area where a conflict between a car driving at high speed and a pedestrian continuously occurs. In a region where the pedestrian road is insufficient, the right of way and accessibility of the pedestrian are limited. In order to secure the safety of pedestrians, the Ministry of Land, Transport and Infrastructure (MOLIT) drew up 'Pedestrian Road Installation and Management Guideline (PRIM Guideline),' which has used as a design basis for the installation of the pedestrian roads in areas such as dense villages in rural areas, connection areas between cities and towns, and outskirts of cities. The current guideline is, however, based on the traffic situations at the time of enactment in 2004, and there are a number of items that do not meet the relevant laws and regulations now and/or are subject to revision in many areas, such as terminology and installation standards. Therefore, in this study, the main revision contents of PRIM guideline, the direction of revision, and the contents of new enforcement were examined and proposed.
\end{abstract}

Index Terms-National highway, pedestrian road, pedestrian road design guideline, pedestrian traffic accident.

\section{INTRODUCTION}

\section{A. Background and Purpose of the Research}

With the economic development, Korea's transportation policy has been mainly focused on automobiles, which leads to building faster and more convenient roads. As a result, bicycles and pedestrians, which were once major traffic modes, were forced to lose their right-of-way. In the 2000s, as global attention has been focused on many problems caused by environmental pollution such as air pollution and global warming, not only foreign countries such as USA and Europe but also Korea have gradually become interested in green transportation including bicycles and pedestrians. In a related move, the existing road-related laws such as the Act of Road and Act of Road Transportation as well as pedestrian-oriented laws have been enacted or strengthened. In addition, road design standards for pedestrians and specifications of infrastructure facilities have been established or added in sub-guidelines and manuals [1].

Despite these efforts, there is still a lack of infrastructure

Manuscript submitted on November 30, 2016; revised May 12, 2017.

Woo Hoon Jeon is with the Korea Institute of Civil Engineering and Building Technology, Goyang-si, Korea (e-mail: cwhoon@ kict.re.kr).

Inchul Yang is with the Korea Institute of Civil Engineering and Building Technology and also with the University of Science Technology, Goyang-si, Korea (e-mail: ywinter75@ kict.re.kr; corresponding author: Inchul Yang). for the sake of pedestrian safety. Pedestrian accidents are still high globally as mentioned in many studies [2]-[5], and so do in Korea where pedestrian traffic accident rate is 4.1 per 100,000 population, which is three times higher than the OECD average of 1.4, and account for more than $40 \%$ of the total traffic accidents. In particular, the entrance to a village on a national highway or the vicinity of a school is a section in which a conflict between a car driving at high speed and a pedestrian occurs continuously, and the right of way and accessibility of the pedestrian are limited in a region where the pedestrian road is insufficient.

To create a safer road environment, the Ministry of Land, Infrastructure and Transport (MOLIT) has enacted and revised "Road Safety Facility Installation and Management Guidelines" for each safety facility on roads since 1995. However, the pedestrian-related infrastructure design guideline was not included in the existing guidelines. In order to secure the safety of pedestrians on national highways, the MOLIT enacted 'Pedestrian Road Installation and Management Guideline [6]'(PRIM guideline), which has been used as a design basis for the installation of the pedestrian roads in areas such as dense villages in rural areas, connection sections between cities and towns, and outskirts of cities. Later in 2007, some revisions were made to the installation location of the pedestrian road, the road crossing components, the structure, and the installation, construction and maintenance of road traffic facilities. In addition, the MOLIT revised some of the contents about the structure, road traffic safety facilities and maintenance in 2010 and 2011. However, since the current guideline is based on the traffic situations at the time of enactment in 2004, there are a number of items that do not meet the relevant laws and regulations or are subject to revision in many areas. Especially, since 2004, when the current guideline was enacted, the design and construction of pedestrian roads and related facilities have greatly increased, and many parts that were not considered at the time of enactment are required to be revised. In addition, there is a need for pedestrian road design standards that reflect the field applicability to apply a plan for installing pedestrian roads to actual sections, through which safe and convenient pedestrian roads can be installed.

In this regard, this study seeks to examine and propose the main revision contents of PRIM guideline, the direction of revision, and new enactment.

\section{B. Research Methods}

This study sought to select major revision items for Korea's PRIM guideline. It presented the direction of revision and new enactment and attempted to establish the direction of the final revision contents in the future. 


\section{SELECTION OF REVISION ITEMS FOR PRIM GUIDELINE}

\section{A. Establishment of Methodology for Selection of Revision} Items

The PRIM guideline was first enacted in 2004. Later in 2007, some revision was made to the road crossing components, the installation location of pedestrian roads and the road traffic safety facilities, and some of the contents about the maintenance were revised in 2010 and 2011. The PRIM guideline has been used as the most detailed criteria for pedestrian road design in Korea, but it has still been partially revised after its enactment in 2004. Since the time when the PRIM guideline was first enacted, the increasing interest in right of way and safety of pedestrians has led relevant ministries and agencies to enact laws, sub-rules and guidelines related to pedestrians. For example, the Ministry of Public Safety and Security enacted a law to establish 'a right to walk', which is a right for the public to walk safely and comfortably, and designate an area where there are many pedestrians, and improvements are required as a walking environment improvement district in 2012. In addition, the MOLIT enacted a law to amend the provision that installs convenient facilities for the underprivileged in traffic in transportation facilities and modes such as stations, airports and bus terminals as a compulsory provision in 2006. In the United States, ADA (Americans with Disabilities Act), which oversees the legislation for the mobility handicapped with respect to facility standards of pedestrian roads, presents the detailed regulations for installation of pedestrian roads, and each local government, such as MoDOT (Missouri Department of Transportation) in Missouri has also established design standards and revised them periodically[7].

With respect to the main items presented in the current PRIM guideline, related laws have been revised continuously since 2004, and therefore it is necessary to review if the revised contents are reflected. In the case of the bicycle and pedestrian road, "Bicycle Facility Installation and Management Guideline" that present the standards for related facilities was enacted in 2010, and some revisions were made in 2015 [8]. However, the revised contents have not yet been reflected in the current PRIM guideline. It is also required to revise the effective walkway width and cross slope, which are the most important factors in the design of pedestrian roads. In addition, there is a need to establish new standards for design elements without specific design criteria, such as a raised crosswalk. Therefore, this study intends to present the direction of revision and selection of items that requires revision with focus on these contents.

\section{B. Selection of Revision Items}

The revision items of the pedestrian road guideline were selected according to the methodology presented above.

1) Amendment of relevant law: Bicycle pedestrian road

2) Revision of major items: Effective walkway width, cross slope

3) Establishment of new items: Raised crosswalk

First, the bicycle pedestrian road was reviewed based on the revision contents of the existing bicycle guidelines. Next, the effective walkway width and cross slope were examined in terms of the appropriateness of relevant laws and design standards. Lastly, the raised crosswalk was investigated with focus on the definition of facilities and evaluation methods.

\section{MAIN REVISION CONTENTS}

The main revision contents of the PRIM guideline are divided into two categories. First, the revised contents of related laws and guidelines were reflected. Second, new contents that are not included in the current guideline were reflected.

\section{A. Revision of Existing Contents}

\section{1) Bicycle pedestrian road}

There are three things that need to be revised on the bicycle pedestrian road. First, the current bicycle pedestrian road has many problems because it is designated by changing the colors of road surface pavement, or the lane of traffic is installed by using the existing sidewalks. The reason is that the bicycles and pedestrian are constantly conflicting in the road surface, and thus the inconvenience of traffic continues. In addition, one factor is that the conflict increases as baby carriages and female pedestrians use the bicycle road paved with asphalt rather than the pedestrian road installed with blocks in a separate-type road in which the bicycle road and the pedestrian road are spatially separated. In particular, if the existing pedestrian road with less than $3 \mathrm{~m}$ is installed as a non-separate type of the bicycle pedestrian road, both bicycle users and pedestrians suffer difficulty in traffic. Therefore, this guideline suggests that the installation of the bicycle pedestrian road should be subject to limitations in order to ensure the right of way and safety of pedestrians. In addition, it is suggested that road signs and safety facilities should be installed in a section where the traffic volume of bicycle users and pedestrians is remarkably low.

Second, according to the bicycle guideline, the bicycle pedestrian road is classified into a separate-type and a non-separate type, and the installation location is divided into an urban area and a riverside area. Therefore, the pedestrian road guideline should also present the widths of the pedestrian road and the bicycle road, and the lateral clearance according to the installation location divided into the urban and riverside areas and the shape of the bicycle pedestrian road.

Third, the bicycle guideline stipulates that the colors used for the pedestrian road and the bicycle road should be different from each other in order to visually separate pedestrians and bicycle users. Therefore, the PRIM guideline suggests that a dark red color should be applied as a color used for the pavement of the bicycle pedestrian road as presented in the bicycle guideline.

\section{2) Bicycle and pedestrian sharing road}

The reason why the effective width of the pedestrian road is important is because it directly affects the pedestrian's traffic convenience and the economical efficiency of road facilities. The establishment of definition for pedestrians is needed to estimate the effective width. A specific definition for pedestrian is not presented in the "Rules about the Road Structure \& Facility Standards", and not only people but also baby carriages and walking assistance chairs specified by an 
ordinance of the Ministry of Government Administration and Home Affairs are included in pedestrians according to the Road Traffic Act [9]. The walking assistance chairs include manual wheelchairs, electrical wheel chairs and medical scooters according to the standard of the medical device prescribed by the Minister of Food and Drug Safety. Therefore, the effective walkway width of the PRIM guideline is presented based on the means of transport with the widest traffic width among the above four transport modes.

In addition, it is possible to present the level of service according to the walkway width through the standard body shape of the pedestrian rather than the wheelchair. Since the standard body shape of Koreans has changed a lot since 1999, the latest standard body shape of Koreans was estimated using the human body standard information database provided by the Korea Agency for Technology and Standards under the Ministry of Trade, Industry and Energy [10]. Size Korea of the Korea Agency for Technology and Standards has proceeded with the Korean anthropometric survey since 1979 and the 7 th Korean anthropometric survey of 6,413 people aged 16 to 69 was conducted on 133 items in 2015. Table I presents the shoulder widths related to the effective width of the total pedestrian roads, which were calculated in the same manner as in 1999.

TABLE I: STANDARD BODY SHAPE OF KOREANS

\begin{tabular}{lll}
\hline \hline Division & Shoulder Width & Chest Width \\
\hline Average & $37.7 \mathrm{~cm}$ & $29.5 \mathrm{~cm}$ \\
90-percentile & $41.2 \mathrm{~cm}$ & $33.2 \mathrm{~cm}$ \\
95 -percentile & $42.0 \mathrm{~cm}$ & $34.3 \mathrm{~cm}$ \\
\hline \hline
\end{tabular}

\section{3) Cross slope}

Generally, cross slope on the road is an important design element that must be secured to smoothly deal with the road surface drainage. In particular, the cross slope on the sidewalk is not only a factor that significantly affects the ease and safety of wheelchair users, but also an important factor directly related to the drainage of the sidewalk. The cross slope should maintain a constant inclination for road surface drainage. However, if the floor of a building adjacent to the sidewalk is actually designed to be higher than the surface of the sidewalk, the specified inclination is exceeded. In such a case, a feeling of leaning toward one side often makes it difficult for pedestrians as well as baby carriages and wheelchair users to travel. Particularly, in the case of a manual wheel chair user, it is difficult to control the wheelchair when crossing the steep cross slope. As electric wheelchair users also consume a lot of battery power, proper cross slope standards are needed to satisfy both safe passage of pedestrians and smooth drainage of sidewalks.

In the current PRIM guideline, the cross slope of $4 \%$ is presented as a standard cross slope. However, as already discussed, the steep cross slope interferes with the pedestrian's traffic comfort, and therefore the cross slope of $2 \%$ is presented as the standard cross slope.

\section{B. Enactment of New Contents}

This study seeks to propose design criteria of raised crosswalk as a new content of the pedestrian road guideline. The raised crosswalk is a facility to induce the deceleration of a car by making the surface of a crosswalk higher than the surface of a driveway, and to ensure the convenience of the pedestrian crossing. Since there are no design criteria of raised crosswalk in Korea, this study attempts to present design criteria through the following steps. At present, three out of six steps were performed, and up to three steps were presented in this study.

STEP 1. Establishment of evaluation items for raised crosswalk standards

STEP 2. Field survey and data analysis

STEP 3. Simulation scenario design

STEP 4. Simulation initial value settlement

STEP 5. Simulation analysis

STEP 6. Presentation of raised crosswalk installation standards

First, the vertical acceleration that occurs proportionally to the passing speed was selected as the evaluation item. The reason is that the raised crosswalk is a physical traffic safety facility to reduce the speed of a driving vehicle, and it can generate the discomfort and psychological speed suppression effect of a driver due to the vertical acceleration. In addition, it was considered that the vertical acceleration is generally utilized as an experimental evaluation item for speed reduction facilities such as a speed bump, which is similar facility to the raised crosswalk.

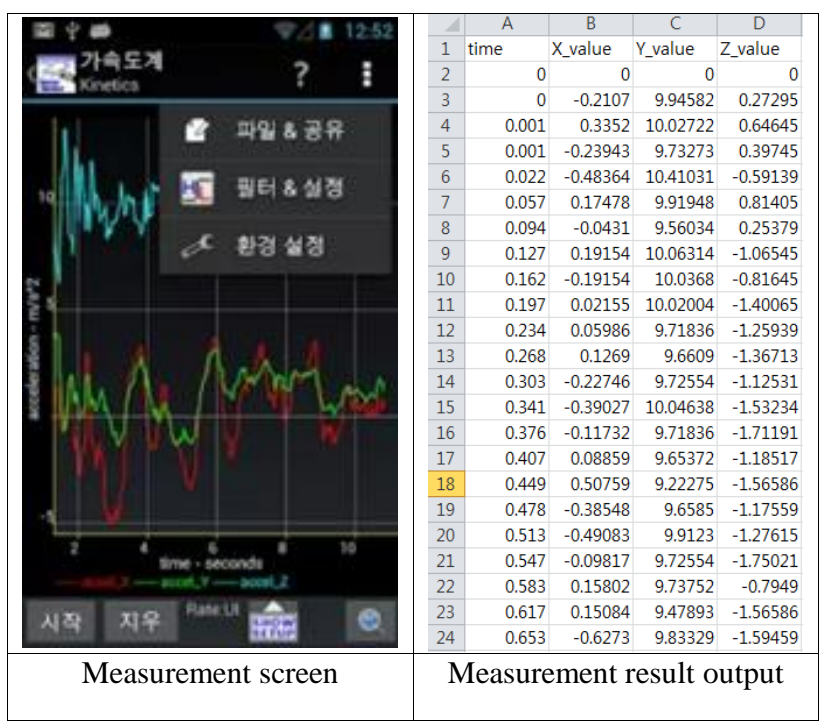

Fig. 1. Vertical acceleration measurement screen and results.

As shown in Fig. 1, Sensor Kinetics Pro(Ver.2.1.2, INNOVE NTIONS Inc, US, 2015), an application that can measure the vertical acceleration based on the a smartphone gyro sensor was used as a method for measuring the vertical acceleration at the actual site in the field survey and data analysis step. This application has been utilized in a variety of fields such as a static balance ability experiment using a smartphone acceleration sensor. In this study, the vertical acceleration that occurs when crossing the raised crosswalk was measured. In addition, the measurement was performed by closely attaching the smartphone to the windshield of the survey vehicle to ensure the accuracy of the vertical acceleration measurement. 
A total of three items were considered as the candidate site evaluation items for the field survey. The first is the ease of the survey, the second is the appropriateness of the regulations related to the raised crosswalk, and the third is the appropriateness of the location. Specifically, the ease of the survey refers to the availability of parking/stop and return for calibration at the investigation stage. In addition, a sufficient distance required for the acceleration should be secured for the investigation by speed. For the appropriateness of the regulations, the height difference of more than $2 \mathrm{~cm}$ and the width of more than $4 \mathrm{~cm}$ from the hump-type crosswalk should be maintained in accordance with the relevant guidelines.

Lastly, the section should be a single road in the form of a two-lane road or a four-lane road with respect to the appropriateness of the location.

According to the evaluation items, the appropriateness for a total of four points was applied as shown in Table II. As a result of the analysis, SITE 3 was suggested as the most appropriate site.

TABLE II: ANALYSIS ON THE APPROPRIATENESS OF CANDIDATE SITES FOR FIELD SURVEY

\begin{tabular}{||llllll||}
\hline \hline \multirow{2}{*}{ Division } & & SITE1 & SITE2 & SITE3 & SITE4 \\
\hline \multirow{2}{*}{ Ease of } & Parking/Stop & $\mathrm{O}$ & $\mathrm{X}$ & $\mathrm{O}$ & $\mathrm{X}$ \\
Survey & Return & $\mathrm{O}$ & $\mathrm{O}$ & $\mathrm{O}$ & $\mathrm{O}$ \\
& Traffic Volume & $\mathrm{O}$ & $\mathrm{O}$ & $\mathrm{O}$ & $\mathrm{O}$ \\
\multirow{3}{*}{ Guideline } & Guideline A & $\mathrm{X}$ & $\mathrm{O}$ & $\mathrm{O}$ & $\mathrm{O}$ \\
& Guideline B & $\mathrm{X}$ & $\mathrm{X}$ & $\mathrm{O}$ & $\mathrm{O}$ \\
\multirow{3}{*}{ Location } & 2-lane Road & $\mathrm{O}$ & $\mathrm{O}$ & $\mathrm{X}$ & $\mathrm{O}$ \\
\multirow{2}{*}{ Selected Site } & 4-lane Road & $\mathrm{X}$ & & $\mathrm{O}$ & $\mathrm{X}$ \\
\hline
\end{tabular}

The purpose of the simulation analysis is first to collect reference parameters that satisfy the measure values obtained from the field survey. Later, the optimum specification can be derived after simulation of the raised crosswalk with various forms. In addition, the simulation can not only further reduce time and costs, but also review various raised crosswalk specifications in comparison with the field survey through the construction of facilities.

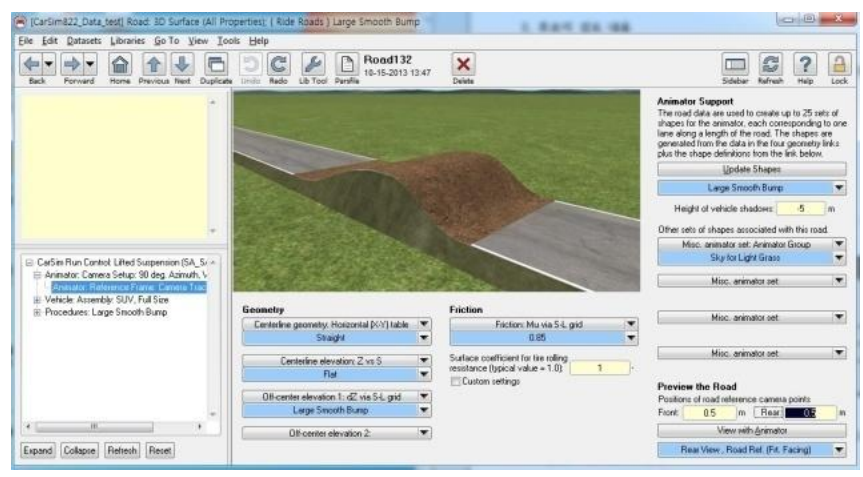

Fig. 2. CarSim execution screen.

Therefore, we used the CarSim program to derive the vertical acceleration according to the raised crosswalk installation scenario to review specifications for the installation of raised crosswalks on national highways. CarSim ver 10.1 of the US Mechanical Simulation Corporation in Fig. 2, which will be used in the simulation review of this study, was first developed by 'University of
Michigan Transportation Research Institute formerly HSRI(UMTRI)' in the 1960s. The main function is a tool that can simulate the dynamic characteristics of a vehicle through a computer, and it can analyze the dynamic characteristics of a general vehicle on a three-dimensional road surface at high speed and display them in the form of an animation or a numerical result.

A total of 27 simulation scenarios for reviewing the raised crosswalk specifications were investigated to derive the optimum specification (see Table III).

TABLE III: RAISED CROSSWALK SIMULATION SCENARIOS

\begin{tabular}{|c|c|c|c|}
\hline \multirow[b]{2}{*}{ Division } & Speed & Height & Length \\
\hline & \multicolumn{3}{|c|}{$\begin{array}{l}\text { Raised Crosswalk shape : Standard-Type Convex } \\
\text { Trapezoid }\end{array}$} \\
\hline \multirow{3}{*}{$\begin{array}{l}\text { Scenario } \\
\text { Combination }\end{array}$} & $20 \mathrm{~km} / \mathrm{h}$ & $7.5 \mathrm{~cm}$ & $4 \mathrm{~m}$ \\
\hline & $30 \mathrm{~km} / \mathrm{h}$ & $10 \mathrm{~cm}$ & $6 \mathrm{~m}$ \\
\hline & $40 \mathrm{~km} / \mathrm{h}$ & $12.5 \mathrm{~cm}$ & $8 \mathrm{~m}$ \\
\hline $\begin{array}{l}\text { A Total of } 27 \\
\text { Scenarios }\end{array}$ & 3 Scenarios & 3 Scenarios & 3 Scenarios \\
\hline
\end{tabular}

\section{CONCLUSION}

This study sought to select the main revision items for Korea's pedestrian road guideline. It presented the direction of revision and the contents of new enactment for revision of the guideline and attempted to establish the direction of the final revision contents in the future. As the related laws have been revised continuously since 2004, the items that are required to review if the revised contents are reflected were mainly selected as the revision items. First, the bicycle pedestrian road was reviewed based on the revision contents of the existing bicycle guidelines. Next, the effective walkway width and cross slope were examined in terms of the appropriateness of relevant laws and design standards. Lastly, the raised crosswalk was investigated with focus on the definition of facilities and evaluation methods. The enactment of design criteria for the raised crosswalk is composed of six steps, and three steps were presented in this study.

The revision directions and revision items of the PRIM guideline presented in this study are expected to be of great help in maintaining the design consistency of the pedestrian road in Korea. In addition, it is expected that design criteria will be presented through various experimental scenarios and experiments for facilities without clear design standards such as the raised crosswalk.

\section{REFERENCES}

[1] Ministry of Land, Infrastructure and Transport, "Comments on regulations of road structure and facility standards," 2012.

[2] F. Helene and G. Yves, "Fatal pedestrian accidents in France: A typological analysis," Accident Analysis and Prevention, 1997, vol. 29, no. 3, pp. 303-312.

[3] Y. P. Rick and B. S. Frederic, "Pedestrian versus motor vehicle accidents: an analysis of 5,000 patients," Journal of the American College of Surgeons, 1999, vol. 189, no. 4, pp. 343-348.

[4] L. Chris and A. A. Mohamed, "Comprehensive analysis of vehicle-pedestrian crashes at intersections in Florida," Accident Analysis and Prevention, 2005, vol. 37, no. 4, pp. 775-786.

[5] H. Hiroshi, F. S. Paul, and F. Baruch, "Traffic accident statistics and risk perceptions in Japan and the United States," Accident Analysis and Prevention, 2000, vol. 32, no. 6, pp. 827-835. 
[6] Ministry of land, infrastructure and transport, "Pedestrian road installation and management guideline," 2011.

[7] United States Department of Justice Civil Rights Division, [Online]. Available: http://www.ada.gov

[8] Ministry of government administration and home affairs, ministry of land, infrastructure and transport, "Bicycle facility installation and management guideline," 2010.

[9] Ministry of government administration and home affairs, "Road traffic act," 2016.

[10] SizeKorea. [Online]. Available: http://sizekorea.kats.go.kr

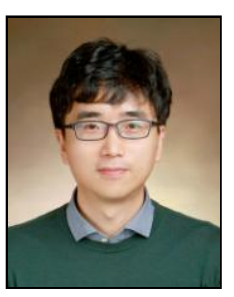

Woo hoon Jeon received the B.S. and M.S. degrees from the Dept. of Transportation Engineering at Hanyang Univ., Korea and Ph.D. from the Dept. of Environmental Planning at the Seoul National University in 2016.

He is currently working as a senior researcher in the Highway \& Transportation Research Institute at the Korea Institute of Civil Engineering and Building. His research area includes bikeway and pedestrian road's planning and design.

Dr. Woo Hoon Jeon is a member of Korean Society of Road Engineers and also a member of Korean Society of Intelligent Transport System.

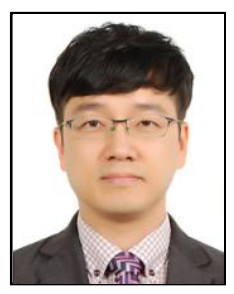

Inchul Yang received the B.S. and M.S. degrees from the Dept. of Urban Planning and Engineering at Yonsei Univ., Korea and the Ph.D. from the Dept. of Civil and Environmental Engineering at the University of California, Irvine in 2011.

He is currently working as a senior researcher in the Highway \& Transportation Research Institute at the Korea Institute of Civil Engineering and Building Technology and also an associate professor in the Dept. of ITS at the Univ. of Science and Technology, Korea. His research area includes GIS-based road maintenance information management, lane-by-lane traffic flow and operation, high-definition digital map.

Dr. Inchul Yang is a member of Korean Society of Road Engineers and also a member of Korean Society of Intelligent Transport System. 